\title{
EUROPEAN IDENTITY AND NATIONAL ATTACHMENT: HARMONY OR DISSONANCE
}

\author{
ANTAL $\ddot{O}_{R K E ́ N} Y^{l}$
}

\begin{abstract}
The paper is designed to answer such questions as where does the development of a new common European identity stand, which countries or regions show stronger or weaker European identification inside the EU, how has this changed over the past decades in the process of the enlargement of Europe, what is the value content of the new common identity, and how is this affecting traditional national attachment and identity. The empirical foundation of our study is the international comparative empirical research series of the International Social Survey Programme (ISSP), in the years 1995 and 2003, which was designed to reconstruct the stock of knowledge of national and European identities in the member states. This study uses temporal and spatial comparison to consider national connectedness and the characteristics of European identity in various countries across Europe. Based on this data, in our paper we make an effort to explore what characterizes national identity in Europe, how people see foreigners and domestic minorities, whether we can identify the development of a transnational or supranational identity that goes beyond national identity, if there is a new frame of identification for people in Europe and to what extent we can expect increasing conflicts between the two types of identities.
\end{abstract}

KEYWORDs National attachment, European identity, nationalism, globalization, multiculturalism, xenophobia, euroscepticism

One of the fundamental questions regarding the process of European unification is whether the European Union will be able to offer its citizens an identity that can "compete" with national identities that feed off historical traditions. This analysis focuses on the question-among others - of identifying those countries in which a strong European identity has developed, and those in which such ties are weak. We further explore whether the time that has

1 AntalÖrkény is professor of Sociology at the Eötvös Loránd Sciences University, e-mail address: orkeny@tatk.elte.hu. 
passed since expansion has changed people's relationship to Europe and how this has affected traditional national feelings and value choices.

This study uses temporal and spatial comparison to consider national connectedness and the characteristics of European identity in various countries across Europe. The empirical foundation of the study is the international comparative empirical research series of the International Social Survey Program, in the years 1995 and $2003^{2}$. These projects explored what characterizes national identity in the world and (particularly) in Europe, how people see foreigners and domestic minorities, and whether we can identify the development of a transnational or supranational identity that goes beyond national identity.

One of the fundamental dilemmas of international comparative research is that information and data obtained on individuals in studies of traditional socialization process within different countries are difficult to compare. (Kohn 1987; Elder 1976) By definition, international comparative work changes the contextual space of traditional sociological analysis. The interpretive field based on the individual is expanded into culturally and politically constructed collective symbolic interpretive fields such as the space of overlapping communities within the national framework, regional similarities and differences, or the interpretation of political and economic communities which form above country level. Issues of the relation to Europe and European identity are typical in this sense: they can only be analyzed as a cross-section of these interpretive fields. Citizens who were socialized in the national communities of the modern world must consider their own relationship with Europe or Europe's various regions, all while a new collective identity is being constructed and old identities are dying out or trying to reposition themselves in new circumstances.

In this study we compare the attitudes of citizens of eighteen ${ }^{3}$ European countries. (Csepeli-Orkeny 1999) These countries are a good representation of the European Union's one-time founders (or those who acceded until 1973), the mixed group of countries that acceded between 1986 and 1995, and the post-socialist countries that acceded under the last expansion. The three groups are heterogeneous, and the countries within the groups vary widely in terms of level of population, economic output and political influence, language and culture and success of modernization and historic paths. However, economic performance, the level of modernity and political relations with the Union (and

2 For more information see www.issp.org

3 For the case of Germany the database made a distinction between former West- and EastGerman territories. The analysis of such allowed for an examination of the connection between political past and national sentiments. 
its goals and its changing political content) more or less unite these various countries. As a result, we can state that common political interests connect the countries to one another ${ }^{4}$. This makes for a useful frame of comparison for the study of whether the intensity of connectivity to Europe has changed in our day, and why (or why not) the citizens of various countries believe in the future realization of a unified Europe.

\section{THEORETICAL CONSIDERATIONS}

The history of the European Union can be described as an expanding and increasingly complex unification process. The beginnings can be seen as a widening economic-market integration process which directly led to phases of military and political cooperation. Political integration made it necessary to express a political community conceptualization of the Union. This entailed consideration of the content of community membership for the ever-widening membership of the camp. A necessary result of this process is that in the past decade the Union has been rethinking member states' political status and their relations with one another. Further, it has had to clarify legal and social norms that tie the community together, establish a European constitution, and make sense of the issue of European identity. (Deflem - Pampel 1996) This last aspect is particularly important for the following reason: despite the fact that the process of European unification has followed rationales of geopolitical realities, the political will of various governments (particularly the great powers) and national interests, the established "alliance" is increasingly in a position where it must rely on the support of citizens belonging to the Union's member states, a support that provides for a wide social and political legitimacy 5 .

4 The first group in the study contains the founder countries like Germany, Italy, the Netherlands, France, and three other countries (Great Britain, Ireland and Denmark) acceding to the EU in 1973. The second group contains countries acceding to the European Union between the late 80s and the mid 90s, like Austria, Sweden, Spain, Portugal and Finland. The last group contains Hungary, the Czech Republic, Slovakia, Slovenia, Poland and Latvia. To control for divergent country characteristics we re-weighted national samples based on the level of population, and we established three groups with similar population numbers. This made it possible to conduct a comparison in which the characteristic demographic parameter differences do not affect the comparability of the three regions.

5 The failure of the effort to draft a constitution draws our attention to precisely this unsolved problem. 
A discussion of the question can take place in basically two interpretive frameworks. The first approach is the study of the actual content of connectedness to the European Union within the context of national identity. The second approach explores possible meanings of unity in terms of globalization, post- or supranational social integration and political legitimacy.

The narrative of relating to the nation-state tries to answer the question of the degree to which European identity is capable of being an alternative to traditional national identity. It further explores the degree of utility and the advantages of European identity for citizens in comparison to the advantages and security offered by national sovereignty and the community of the political state on national ground. Over the last centuries of capitalist modernization political rule and legitimacy, as well as social integration, have all been organized within the framework of the nation. The weight and significance of the status of political nation state has significantly declined over the past decades within the process of European unification. The advance of economic globalization has rendered meaningless the organization of markets on a national basis. European political institutions significantly limit the political sovereignty of member states. Cross-border labor markets and education systems offer people unlimited transnational mobility, while the flow of information, social communication and a "borderless" global media constellation brings into doubt the value of knowledge based on the nation alone.

Changes in conditions have led to various prognostications. There are some who describe this process as a kind of devolution of the traditional nation state, which does not exclude the possibility that economies and politics organized on national foundations will disappear altogether. In this approach the unified Europe appears as an alternative to the national community. The process of Europe becoming a "nation state" goes beyond the ideas of economic and political unification and entails intellectual and cultural communities formed of the continent's ethnically, linguistically, and culturally pluralistic world, all making possible the birth of a European identity. At their births modern nation states required common myths, shared historic memories and a culturallinguistic identity to create unity from widely divergent groups. In a similar way, Europe must also find its common roots in Judeo-Christian traditions and ethics, the intellectual inheritance of the Renaissance, the Enlightenment, Romanticism and Classicism, in individualism, humanism and rational thought, and in those characteristics that distinguish Europe from the rest of the world. The concept of a united Europe formed of pluralism must be based on the idea of branches sprouting from a common tree, where the starting point is not ethnicity but shared cultural traditions (Smith 1992). 
We can take a different approach to belonging to the European Union in a national identity context. In this case the advance of European economicpolitical integration and the transformation of the EU member states can be seen as a parallel to process of the rebirth and reinterpretation of the nation, the strengthening of the role of cultural-ethnic identity, or in a more extreme version the development of a kind of ethnic nationalism (Brubaker 1996; Richmond 1996). In this reading the role of national symbols and mythologies and ethno-history in the birth and survival of nations, or the definitive role of cultural resources, values and traditions in nationally based social integration, does not lose its pertinence for people and countries. Its significance may even increase. According to this view European identity and changing national identity are forming a symbiotic relationship. The theory of the harmonious coexistence of European, regional and national identities rests on the definition of multiple identities, according to which dynamic national identity based on old ethnic, linguistic, cultural and historical roots can combine with regional communal consciousness and shared European culture, value systems and historical roots to form a developing supranational identity (Smith 1992). Events of the previous decade - like the political misery surrounding the ratification of the European constitution - have cast a shadow over this optimistic point of view and have shed light on the inconsistencies or impossibilities inherent in it. Examples of the inner inconsistencies of the multiple identity approach include the continuous reinterpretation of Europe's geographical and spatial borders, the inadequacy of geographic and physical and social-psychological factors, the inner tensions of culturalsymbolic contents, the debate in reference to Christian roots in the preamble of the planned constitution, tensions resulting from religious divides between Muslims and Christians, debates over openness or closure springing from increased migration to Europe, and problems arising from Europe's linguistic pluralism.

A different approach to membership in the European Union and European identity does not look to the continuation of traditional national forms of political and social integration and its inherent tensions, but instead seeks the possible content of European identity in new phenomena like the economy, the labor market, the transfer of knowledge, the radical new framework of global social communication; i.e., it takes into account the increasing importance of global identities. According to this, people are ascribing increasing significance to values which have no direct relation to traditional nation state norms (Habermas et al. 1998). These include human rights, the rule of law and democratic norms, pluralism and the search for social consensus, social justice, social rights and the right to a dignified life and self-determination 
for cultures and minorities (Schlesinger 1996; Wallace 1991). These go beyond the national framework and make possible the creation of a kind of supranational identity framework. After the failure to ratify the European constitution, Ulrich Beck and Anthony Giddens released a statement in which they claimed:

"Let us start to think of the EU not as an "unfinished nation" or an "incomplete federal state", but instead as a new type of cosmopolitan project. People feel afraid of a possible federal super-state and they are right to do so. A resurgent Europe can't rise up from the ruins of nations. The persistence of the nation is the condition of a cosmopolitan Europe; and today, for reasons just given, the reverse is true too. For a long time the process of European integration took place mainly by means of eliminating difference. But unity is not the same as uniformity. From a cosmopolitan point of view, diversity is not the problem; it is the solution." (Beck-Giddens 2005:1)

Beck and Giddens' point can be interpreted as saying that Europe must represent those leading social values that can define a direction for human, social and civilizational content and the aims of a new alliance. Nation states can provide the net of cultural integration. They can together offer a new and modern identity framework for the citizens of the Union. Another difference between the supranational identity (that spans nations) and the traditional national identity based on blood and ethnic roots is that, while a national framework led to the establishment and flourishing of ideologies of exclusion, distancing from others and differentiation, and ethnocentrism, European identity must be based on concepts of liberty, openness, partnership and the joint maximization of social utility.

These ideas, however, are currently the domain of wishful thinking and do not describe reality. When considering what is common across members of the Union, one is more likely to reach the conclusion that linguistic, ethnic, religious, legal, economic and political differences far outweigh common characteristics. This appears to be an obstacle to community formation and the birth of a common European identity. At this point, however, we must distinguish between collective social identity and the individual dimension of identity. While the former is prescriptive in nature and is characterized by permanence, principle and substance, and its acceptance is guaranteed by both legal and cultural sanctions, the latter is characterized by a situational nature and flexibility which can of course change, be replaced, or even be suspended by the individual. The glue of membership in the community and identity no matter what type of social identity we are considering - is dependent on whether we take a collective or individual approach. 
When considering the personal ingredients of European identity, we must differentiate among several marked dimensions.

One such dimension is the role of individual utilitarian aspects (Gabel 1998; Gabel-Palmer 1995). A motor of the positive judgment of group membership is whether membership results in profit or loss for the individual. An important message of membership in the European Union is that on both an individual and societal level, many benefits are achievable that are less attainable (or unattainable) in the framework of the traditional nation state. The balance sheet of advantages and disadvantages is, however, shared unequally across society. As a result, the identity effect of utilitarian calculations is statusdependent, and while certain segments of society can strengthen the positive identity of group membership, other segments will weaken or even bury it.

Another key source of identity is the ability of the individual to be able to identify with the cohesive and characteristic norms of the group. An important test of European identity is whether or not it is capable of providing values and models of social integration that distinguish the Union's community from communities based on traditional ethnic and national grounds and their inherent values. Various analyses attempt to distinguish between nationalist, materialist and post-materialist values ${ }^{6}$.

The literature treats the role of individual cognitive mobility as an aspect of the strengthening of European identity. (Inglehart 1970; Gabel 1998) This theory stresses that effective political socialization can significantly strengthen political consciousness, political knowledge and political communication. These can in turn contribute to making supranational identity attractive, giving it more pull when compared to traditional ethnic-national or even local identities.

The next factor is the relation of the individual to the political community and the role of political commitment (Franklinet al. 1994; Franklin et al. 1995). This is ingrained in the attitudes of those who are committed or opposed to the process of unification, the attitudes of political movements of eurosceptics, party preferences, or even more generally, acceptance or rejection of the political system. The past few decades have provided numerous examples of anti-Europeanism within quite divergent political views (e.g., the radical rejection of globalization, increasing nationalism or anarchism), whereby behavior radically opposed to the unification project emerges.

Finally, another factor strengthening identity is the role of inheritance and socialization, which is a more significant factor in countries that have long been members of the European Community and where the existence of the

6 This concept was originated from Inglehart (Inglehart 1977) 
Union and its community-formation role were beyond a doubt. This factor and its effect may become more significant in a unifying European identity - it is already significant today - as seen in life period and intergenerational studies.

The combination of factors described above effect individual attitudes and human behavior. This in turn affects whether Europe's citizens will view the newfound European community as merely an effective rationalization of economic and political cooperation - one that assists the improvement of living standards, but nothing more - or as something more, as a kind of cultural, normative choice, social community.

The following analysis will consider some elements of this complex question. As a first step we compare the level of attachment to Europe, and then reconstruct the personal cognitive background of attachment.

\section{THE FRAMEWORK OF INTERPRETATION}

The empirical comparison of European and national identities requires the clarification of a number of concepts. First we must consider how sociological and social-psychology studies have tended to differentiate between individual identity and collective and social identity. Personal identity is a psychological phenomenon of definitive significance in the development of a person's image of self. Its final form is developed through socialization (Erikson 1956). Personal identity contains differentiated traits and characteristics, but in terms of its role it is essential for social interaction and for integration into various social groups. It is continuously reshaped in the complex system of inter-group relations. Social or collective identity is a framework of the interpretations and conclusions of a group, including the characteristics of the group, the conditions for membership in the group, and the attributes of separation from other groups (Hamilton-Sherman 1996; Karolewski 2006). Sociologists interpret collective identity as a social construction that forms during the development of a group, that is founded on accepted collective knowledge, that defines the rules of behavior within the group, and that demands that members accept rules and norms (Tajfel 1982). These social representations make it possible for the group members to integrate into the group, to report on the group, and to be cognitively and emotionally accepted.

When discussing forms of identity such as European or national identity, this must be interpreted as a representation of both collective and individual identity. The former describes the self-image framework of the European or national identity, while the latter pertains to the meaning of these forms 
of association for the individual and the degree to which content elements of European-ness or national association are built into the individual's selfimage and to what degree they enrich that self-image.

The various frameworks of social or collective identity result in a jumbled inter-group picture for the individual, one which plays a definitive role in the individual's cultural socialization and integration. These reference frameworks jointly affect the individual's self-image. They often compete with one another, while at other times they complement one another or form a harmonious whole. They constantly change according to which aspects and reference points are strengthened or weakened by the individual's current life situation, roles and behavior.

From the point of view of our empirical analysis we must distinguish among four levels of the cultural field of social identity. The narrowest identification field is the local life space, which includes place of residence, workplace, and the microenvironment of everyday activities. This mostly means the town in which one lives or the city or territory to which one relates in several ways. This is the space where our inter-group interactions are most dense, where we have personal relations with the other members of the social in-group that bind us. The next framework in forming identity is the country and the national space that makes the country culturally and politically unique. Both instrumental and symbolic factors operate the binding system of the national community. The former include the political administration system, shared norms and the legal system, the economy's national borders, shared infrastructure, and the network of services and social care. The latter is typified by a common language, cultural and ethnic roots, memory of a common past, practices and traditions, and the feeling of emotional bonds.

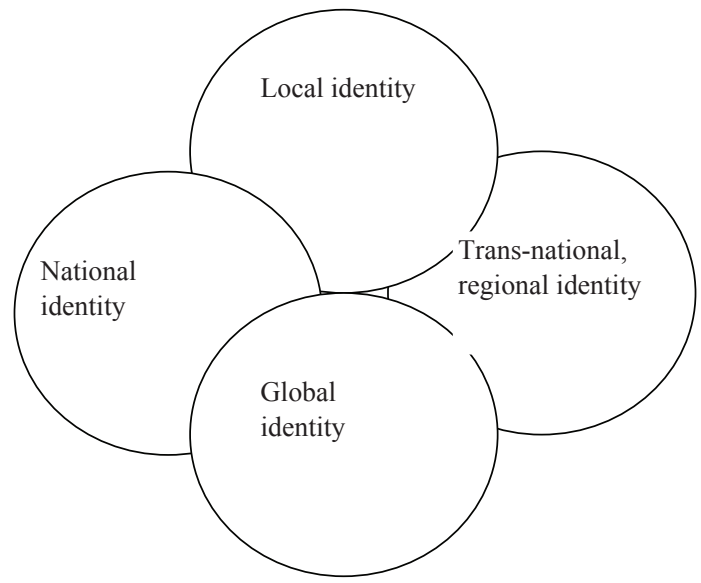


The traditional frameworks defining local and national identity have been pulled apart by the unstoppable force of globalization over the past century. It is in this context that the idea of integration serving a common political European ideal makes sense, as does the concept of a global space that transcends all earlier borders and defines people's lives. This not only opens up a radical new perspective in interpersonal and inter-group relations, but can force the social necessity of European and global identity.

The four cultural fields of social identity illustrated above together form the self-identity of individuals and groups and of the membership of individuals in groups. The relations are characterized by pluralism, complexity and contextualization, while counter-effects like shunning, competition, differentiation and exclusivity are observable. Before we investigate the characteristics of the four identity types across countries, we must consider the uniqueness of various cultural bearings.

The national framework and view, or the traditional importance of national identification, came into existence as a political concept in modern times. The challenges of modernization necessitated new forms of wide and complex integration on national grounds. Such challenges included the birth of the modern state, administrative and bureaucratic integration in a strictly defined territory with borders, the market-based coordination of the economy and the development of national capitalism. This necessitated political and social integration that was capable of integrating the entire political community within the borders, establishing a public sphere and civil society, and introducing forms of individual and collective political participation based on the principle of equality. The political state based on the spirit of the national community established the modern status of citizenship, while national identity provided the institution of citizenship with political, social and cultural content (Gellner 1983). These frameworks are being pulled apart by the post-industrial age. National borders are more easily crossed, thus weakening the framework of national isolation. Traditional political separation based on national cleavages is being replaced by cooperation and joint policymaking. Economic isolation and national economy protectionism are replaced by global economic processes. In light of the transformation of national identity the most important change was the replacement of traditional cultural homogenization and dominance by cultural pluralism, multiculturalism based on ethnic and cultural coexistence, and the pluralization of identity. The space of political nationalism was increasingly taken over by ethnonationalism (BrubakerCooper 2000), the communal role of national solidarity was replaced by alternative solidarity-based communities. Shared national ethno-history, common cultural roots and even the shared national language all begin to 
lose some of their significance. The greatest challenge to the transforming national ideal and its related national identity is to what degree it can survive the transformation, what new forms cooperation, solidarity and cultural life within the national framework can take, and what shared values will sustain the significance of the coexistence of citizens.

The counterpoint to the national perspective is the global perspective. The past decades have not only seen the increased intensity of the globalization process in political, economic, migration, and flow of knowledge and information, but the change has brought about a new global identity as well. Signs of this include the salience of universal human rights, tolerance, pluralism, the universalization of the norms of democracy, the respect for human dignity, social solidarity and social justice norms. The defining aspects of globalization are multiculturalism, collective cultural rights, global access to knowledge, global communication and network building, and the global character of consumption. At the same time the global identity faces serious challenges. Such challenges include the issue of poverty, the strengthening of inequality across the globe, environmental and social risks, and importantly, the increasing pace of migration and its inherent demographic challenges and attendant cultural conflicts.

The European perspective, i.e., the unification of the states comprising the Union, on one hand goes beyond the national context, but on the other hand can only partially be connected to the actual trends of globalization. The promise of the Union is that of a continually expanding deepening process that offers integration in legal, economic and political terms for member states and their citizens. Innovation can help Europe become more competitive in many fields. The option of life paths that cross national borders offers opportunities and mobility for all those who are willing and able to convert their resources in transnational space. Another attraction of the Union ideal is that it rewrites the system in which political nation states traditionally competed, strove for dominance and sought to weaken one another. Instead, it establishes regional and supranational cooperation that transcends national borders, partnership and shared responsibility among member states, all while making efforts to even out inequalities between nations or to close the gap between member states. This naturally manifests itself in identity terms. For its citizens the Union characterized offers success, wealth, movement in an open space, wide opportunities, and increased security, which in turn can result in decreasing the individual and collective disadvantages and inequalities traditionally found in the national space. The Union's political ideal can open space for the formation of new forms of political identity, mostly through pluralism and new opportunities for political participation. However, identity formation 
is seriously limited when trying to work out common cultural values and roots and the emotive and symbolic aspects of "identity consciousness". Shared cultural identity, common language, shared ethno-history and cultural memory are all lacking. Increasing cultural diversity and inherent cultural conflicts only make the task more daunting. While national categorization draws unequivocal lines between "insiders" and "outsiders", between national belonging and foreigners, the ideal of a united Europe cannot draw borders with certainty, as such border concepts constantly change. Culturally, the lines dividing European culture from non-European cultures have eroded and been constantly questioned. But political unity and pluralism as a basis for a European political community is not without its own conflicts. To this day it is unclear whether the bordered political space of Europe defines a kind of unified social space, or whether Europe's social base is nothing more than a virtual "community". It is not clear what social ties and values make possible relations among European people. Nor are the grounds for exclusion of people or groups of people from the social space always clear. The inner tensions of European identity are rooted in such cultural and social problems. The answers to these problems will define the direction in which the European Union will change in the future and European identity itself.

\section{ASSOCIATING WITH NEW EUROPE AND THE LEVEL OF NATIONAL AFFILIATION}

Having considered the theoretical aspects and the framework of interpretation we can now begin to empirically study the roles of national, European and global identities in the mechanism of social identification. This sociological approach, through reconstructing the components of association, differentiates between unconsidered, obvious and seemingly natural national identity in opposition to national identity presenting or reproducing constructed ideological elements (Csepeli 1992). First, let us consider the regularity and intensity of association respondents have in a spontaneous emotional manner in terms of their own national group and Europe itself.

Through operationalization we considered the internal, emotional and unconsidered experience of socially constructed distance as a starting point. We tried to make this understandable to respondents by using the term "closeness". Association is possible by starting in local space and moving 
outward to cover all Europe in concentric circles ${ }^{7}$. But while locality defines a concrete physical and geographic environment, concepts like nation and particularly Europe are constructions that encompass historic, symbolic and emotional factors.

The following graph illustrates how association with various levels develops in various European countries in the examined periods.

Figure 1 Patterns of a spontaneous local, national, and European identification by countries, cluster types

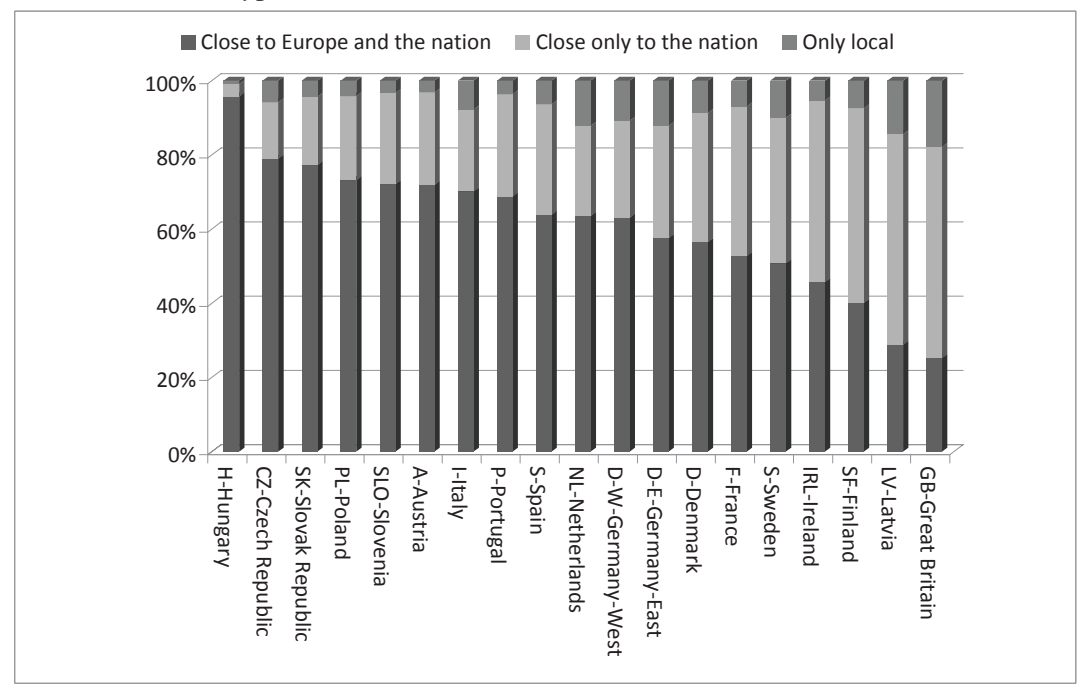

It can be seen that the national framework binds the members of communities tightly in most all the examined countries. Differences are apparent when considering whether this is paired with a European association as well, or whether the borders of identification are closed at the borders of the nation. It is surprising to see that the recent accession countries show the strongest dual identification (Hungary, Czech Republic, Slovakia, Poland, Slovenia), while the attraction of European identity is weakest in the far reaches of Western Europe (Great Britain, Finland, Ireland) and in Latvia. Paradoxically, the longer a country has been a member state of the Union, and the longer it has enjoyed the advantages of diminishing national borders, and the freer its

7 The original items we used in the questionnaire were the following:," How close do you feel to your city" (Very close, close, not very close, not close at all, can't choose); "And to your country?"; "And to your continent (Europe)?" 
citizens are to cross over to the rest of the countries, the stronger the emotional attraction to the national space (or the weaker the feeling of closeness to the open European space). Those countries that spent long decades or even centuries on the periphery, or were left out of the mainstream of European modernization, experience their national identity in conjunction with a strong emotional tie to Europe.

The concentric circles of association are not random. They follow a strict logic that establishes the attitudes of people. The construction of identity models on top of one another is partly thanks to the structure of society and is a result of parallel membership in and relations to groups. On the other hand it assumes that primary, secondary and other group memberships and the identities inherent in them are structured hierarchically (Tajfel 1982).

Regarding emotional association in the circle of older member states, we can observe "euroscepticism" showing in the cognitive space of some identification frames. Given identity types can be differentiated according to the values and goals that establish the identification frame. According to this, the national context means inner homogenization, separation, closing and protectionism. This is in contrast to the European relation frame, which is quite the opposite, emphasizing cooperation, self-restraint and the role of common interests. The global identity context is similar, where global-sized preferences and regulations (economic, security policy, or environmentalism) play the defining role. If these three identification frames are compared based on the time countries have been members of the Union, we see big differences in emotional attachment compared to earlier trends ${ }^{8}$.

8 The original items measuring national, European, and global identity were the following: "(R's country) should limit the import of foreign products in order to protect its national economy"; "(R's country) should follow its own interests, even if this leads to conflicts with other nations"; "Foreigners should not be allowed to buy land in (R's country)"; "(R's country) television should give preference to (R's country) films and programs", "For certain problems, like environment pollution, international bodies (eg. UN, EU, WHO) should have the right to enforce solutions". Concerning to European identity see items at footnote 15. Agreement or disagreement with the statements was measured on a five point scale. The indexes were made by simple aggregation. 
Figure 2: National, European and global identities in parallel, scale average

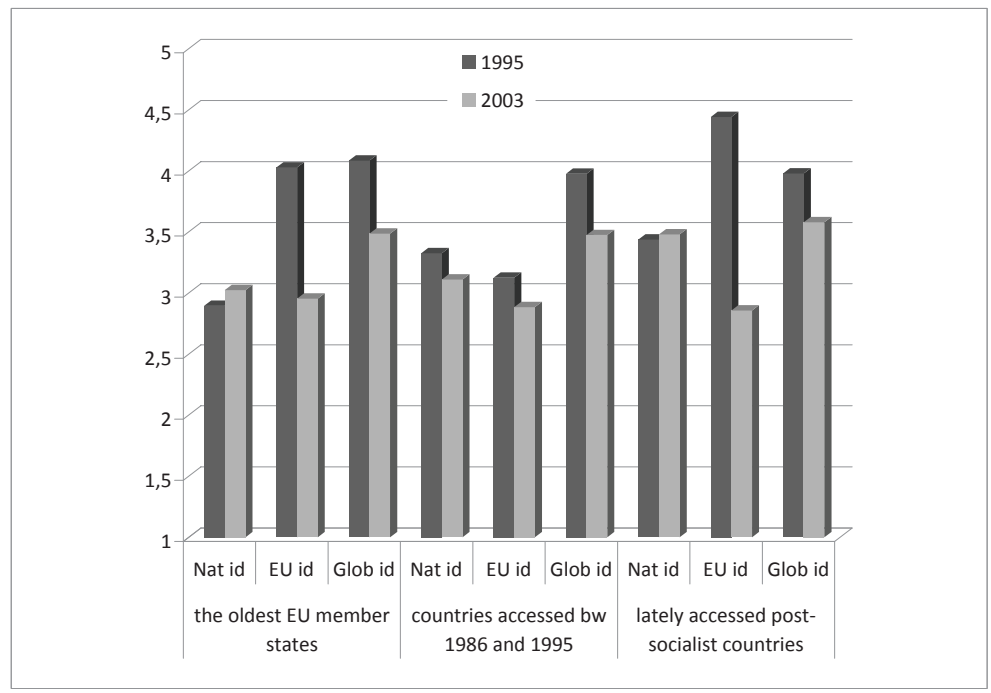

In view of globalization there are hardly any differences among the three groups of countries. A strong acceptance of globalization is evident in all three regions, even despite a slight decrease in such acceptance over the two examined periods. National identity and nationalism are stronger (and more enduring) the later a country joined the European Union. It appears that the cognitive content of belonging to a nation is a strong incentive in the service of the citizens of newly acceded countries, convincing Europe to finally take them into the fold. At the same time the biggest change occurred in associating with Union values. The weight of European Union identity falls dramatically for founder nations and new members. For the latter the strong positive emotional associations and expectations regarding Europe, and the contrast of that state with the difficulties and problems of accession is what leads to this dramatic drop.

In sum, neither the national, nor the European nor the global identity was dominant. The respondents displayed some ambivalence towards all three, and significant differences across countries and regions are evident only in the level of change over time. Such change was strongest for new member states, which may be an indication of identification uncertainty and inconsistencies. National association, however, is stable and persistent. 


\section{CONFLICTING VALUES AND VALUE-BASED CULTURAL CONFLICTS}

According to research on the topic, pride is an emotional aspect of all nations. In this section we will consider what cognitive content is mobilized in the identity consciousness of the members of given European nations by measuring spontaneous identification of national pride, all when the respondent tries to convince him/herself and others of his/her membership in the nation.

We chose the topics such that the verification of national pride was possible not only for those whose national past and present made it possible for all to experience unequivocally recognizable results and successes, but also for those whose pride consciousness may be rooted in murkier areas, transferred from the past to the present, and generally difficult to measure empirically, to be able to express reasons for national pride. Naturally all nations have their own reasons for pride, but we shall see that there are patterns governing which nations' citizens refer to primarily which kinds of content when asked why they feel pride in their national affiliation.

We listed ten cognitive elements and asked respondents living in the given countries to grade their level of pride in the element on a four-point scale ${ }^{9}$. The dimensions offered on one hand referred to the definitive aspects of European modernization (economic output, political influence, defense of human rights, social care) and on the other hand covered the cultural roots of national identity through references to narrative symbols (arts, science, history, sporting achievements). We were primarily interested in whether we could map out a national value diagram and self-image using the offered topics, and if yes, whether we could identify country or region-specific characterizations on the value map.

We managed to integrate the ten topics into three value profiles. This differentiation partially followed the concept designed by Ronald Inglehart in the 1970s (Inglehart 1977), where material or modern value orientations were distinguished from postmodern value orientations. In the first profile we listed those values that played a key role in the birth of modern industrial societies (economic success and political influence), while the second profile

9 The ten cognitive elements in the questionnaire measuring national pride were the following: the way democracy works, country's political influence in the world; country's economic achievements; its social security system; country's scientific and technological achievements; country's achievements in sports; country's achievements in the arts and literature; country's armed forces; its history; country's fair and equal treatment of all groups in society. The answers were measured on a 4 point scale. 
contained postindustrial social values like social security and solidarity, and the protection of human rights. We added a third profile that we called traditional value orientation ${ }^{10}$. We used a cluster analysis ${ }^{11}$ along the profiles to seek out value combinations that would allow us to draw the national pride maps of the given countries.

The map drawn of tradition national and modern European values clearly separates Europe's western and eastern halves. The most surprising result was the fact that the intensity of pride feelings is quite strong in the West and that the source of feelings of pride was moving from traditional modernization successes toward postmaterial accomplishments. This is particularly the case for small countries or for those who experienced rapid development, like the Netherlands, Denmark, Austria and Ireland. Great Britain and France were more divided in this regard, and they often referred to national cultural and symbolic accomplishments alongside traditional modernization achievements. Germany - particularly its Western half - was an exception to this: Germans were proud of their country's modernization achievements to nearly the same level as its postmaterialist achievements, though the importance of this feeling of pride was rejected by a significant proportion of the respondents.

Figure 3: Value map of national pride, cluster types by countries, percent

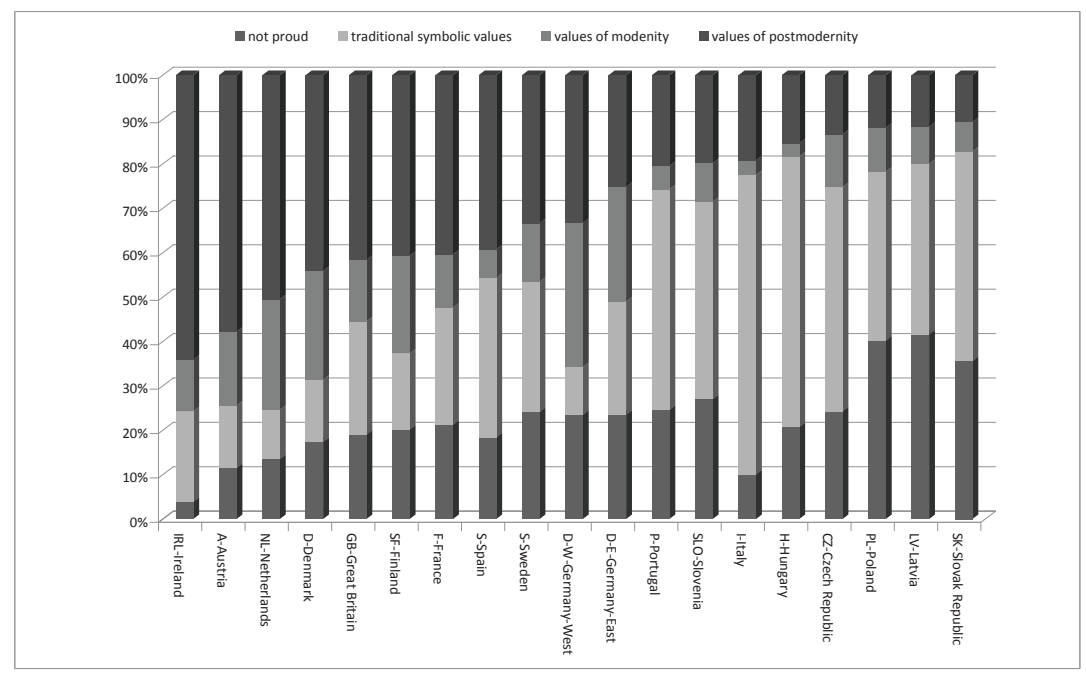

10 The confirmatory factor analysis confirmed the existence of the three different profiles. 67 percent of the total variance of the included variables was described by the three new variables.

11 The three latent variables were clustered using K-means method. 
In contrast to this, the feelings of pride among citizens of recently acceding post-socialist countries could not be mobilized by any modernization topics. The modern accomplishments of their countries were not deemed to be important and were not valued deeply, which was in contrast to the weight of those values which were difficult to interpret and mostly celebrated subjective memory of common national pasts, emphasized the uniqueness of the country's cultural heritage, or honored the individual accomplishments of those who were able to break through the limitations of their underappreciated communities. This kind of deficiency complex can easily undermine communal self-respect, and is manifest in the fact that Eastern Europe contained the highest proportion of those who claimed they felt no sense of pride in the accomplishments of their countries.

To summarize, we can clearly see how divided the countries are in terms of their self-images and value preferences. This causes us to be skeptical of unification. It is unclear how the cognitive divide between countries or regions might be successfully bridged, or how the value base of a unified identity might be created ${ }^{12}$.

This dilemma indicates another aspect of emphasized European identity, that of the heightened significance of multiculturalism. The social embedding of the multicultural point of view was measured by studying attitudes toward immigrants. Immigrants represent foreigness in a modern, globalizing world. Their acceptance or rejection is an important measurement of the tolerance of difference. The idea of a united Europe, which was founded on the principle of the acceptance and integration of ethnic, religious, linguistic and cultural pluralism, signals a definitive role for tolerance. Can we get a handle on value preferences by studying attitudes toward immigrants? We can test this negatively by examining the level of acceptance of xenophobia and attitudes supporting the rejection of immigrants.

The occurrence of xenophobia was measured using traditional stereotypes like agreement with statements like: immigrants are responsible for growth in the crime rate, or immigrants take jobs away from local people. Such

12 As the EU initiates social, political and economic reforms aiming to reach a more equal geopolitical relation between member states, Inglehart expected that the idea of the EU will get support more among postmaterialists. Other researches, however, were only partially supported by the Inglehart hypothesis: in the old member states the theory was validated, while in the countries which joined later, postmaterials turned out to be less supportive of the integration process as the materialists. Our research seems to confirm this as well: in the West we found a weak correlation between postmaterial values and support for the EU. In the post-socialist countries, however, materialist values have an effect on the support of the EU. About the details see: Anderson et al. 1996; Janssen 1991) 
fears can be coupled with political considerations like claiming the number of immigrants is too high, or that the government spends too much money supporting immigrants. Openness based on the toleration of difference is capable of acknowledging the economic advantages brought by immigrants, and feels that immigrants enrich the national communal culture. These attitudes were measured by six items in the study, each of which fit in well with a latent factor structure ${ }^{13}$. We then constructed a general xenophobia value scale by aggregation, where a high score indicated virulent rejection of immigrants and a low score indicated intensive acceptance.

Another group of questions measured whether respondents preferred full assimilation strategies or - in opposition - integration strategies based on the protection of cultural difference as desirable when applied to ethnic minorities ${ }^{14}$. High scores on the aggregated assimilation versus multiculturalism scale indicate a preference for assimilation while low scores indicate a preference for integration. The following figure lays out the strength of xenophobia and assimilation strategies by country.

13 The original questions asked respondents how much they agreed or disagreed with statements about migrants. The statements were the following: "Immigrants increase crime rates; "Immigrants are generally good for the economy of the (R's country)"; "Immigrants take jobs away from people who were born in (R's country)"; Immigrants improve the host society by bringing in new ideas and culture"; "The number of immigrants to the (R's country) nowadays should be increased or reduced"; "There are too many immigrants today living in the (R's country)".

14 The original items in the questionnaire were the following: "It is impossible for people who do not share [Country's] customs and traditions to become fully [Country's nationality]"; "Ethnic minorities should be given government assistance to preserve their customs and traditions"; "It is better for society if groups maintain their distinct customs and traditions or it is better if groups adapt and blend into the larger society". 
Figure 4: Xenophobia and multiculturalism, scale average by countries

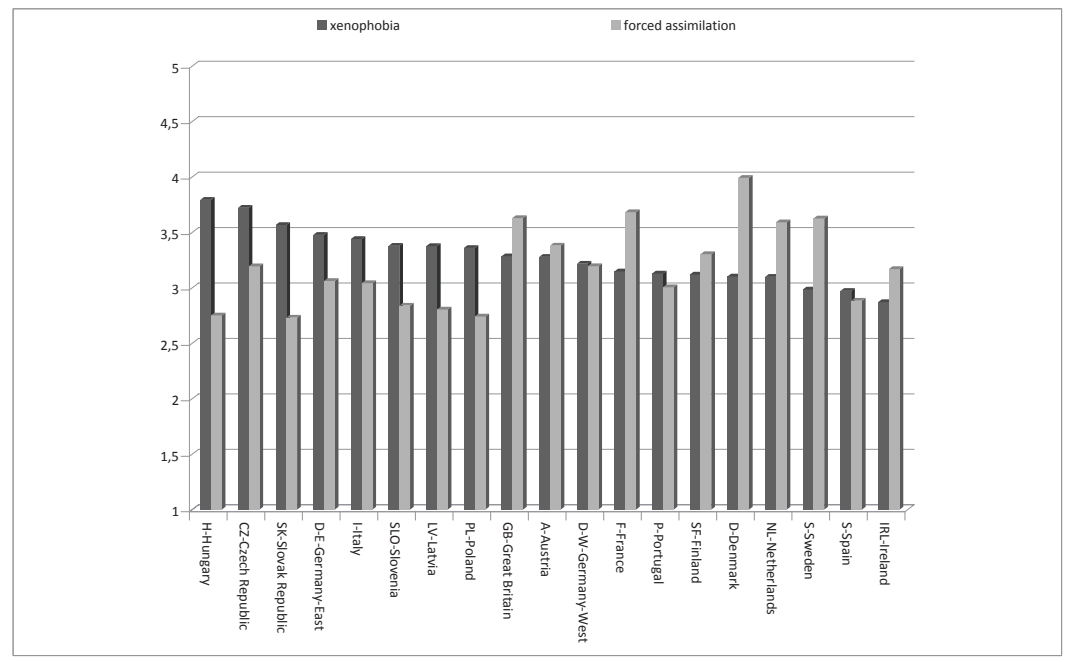

Europe is again split in two, in a way that is similar to the split along pride lines. The developed Western European countries are relatively open to immigrants - though it would be a stretch to call them enthusiastic. The lowest level of rejection was measured in Ireland, Spain and Sweden, where the xenophobia indicator was at a medium level. Contrasted to this are the new members from the former socialist block. The citizens of these countries - including those in the Eastern part of Germany and surprisingly Italians too - were impetuous and rejecting of foreigners. At the same time, the measurable antipathy toward foreigners in the Eastern half of Europe was not paired with an assimilation strategy for domestic ethnic minorities, while in the more modernized West tolerance was paired with a zest for assimilation policies. This was observable in Great Britain, France, the Netherlands, Sweden, and particularly in Denmark. This mixed picture is likely due to divergent sociological and socio-psychological processes. Western Europe, which has raised the postmaterial ideal of multiculturalism up its flagpole, is concurrently a target area for ever increasing immigration. In many places this results in structural xenophobia, behind which we see social tensions that arise from mass migration and cultural conflict. Official policies of accepting cultural difference and pronouncing tolerance are in vain where immigration has resulted in impassioned rejection or vehement expectations of assimilation. In Eastern Europe, xenophobia functions according to a different logic. Here migration does not present a significant social challenge. 
The number of immigrants is low. However, the national rebirths following the regime transformations and their accompanying searches for identity were often based on cultural homogeneity. This search for self-identification treats foreigners as a nuisance, which follows logically from the suspicion of the few immigrants present, the sometimes violent rejection of difference (from the majority), all while the assimilation of national ethnic minorities is not necessarily a goal desired by the majority of society.

Europe has proclaimed the unprecedented goal of establishing cultural integration based on the (ever expanding) foundation of cultural pluralism. But in daily life cultural flashpoints not only refuse to go away, but seem to be causing more and more conflict. It appears that the maximization of efficiency is an easier goal than that of peace between divergent cultures.

\section{ATTRACTIONS AND CHOICES}

To this point we have presented some affective (associational) and cognitive (sense of pride, openness and acceptance of others) factors, as well as aggregations of such, which well illustrate the variants of content elements of association and identification present in the collective consciousness of various European countries and the identities of their citizens. Our data clearly shows that Europe's diverse historical and political regions, or its countries of various cultural and historical backgrounds, are significantly different, which brings into doubt the possibility of unifying a consciousness.

Another analytic logic would have us create groups along identity factors from among all the populations of European Union member states. We would then continue to examine the degree to which such groups occur in the countries of the Union ${ }^{15}$. The members of these groups would connect their identity construction and value orientation in unique ways.

In this analysis we made use of cultural association and numerous cognitive and affective elements of social identity. When searching for types we made use of emotional components of European and national association ${ }^{16}$, the level

15 Support for the European Union was measured by the following items: [Country] should follow [European Union] decisions, even if it does not agree with them. EU should have more power than national government If there were a referendum today to decide whether [Country] does or does not become a member of the [European Union], would you vote in favor or would you vote against?

16 See references for emotional components in footnote 7 
of ethnocentrism ${ }^{17}$ and national pride ${ }^{18}$, the strength of political and economic nationalism ${ }^{19}$, and attitudes toward the assimilation of minorities and the rejection of difference ${ }^{20}$. We used these in a cluster analysis ${ }^{21}$ that resulted in three characteristic orientations.

The first characteristic identity type can be called a cosmopolitan patriot in the footsteps of Habermas (Habermas-Ratzinger 2005). The members of this group feel closest to the theoretical construct of the European citizen. They typically have a strong affinity for Europe, are ambivalent about globalization, and reject traditional political nationalism to at least a moderate degree. The cosmopolitan patriot is tolerant of foreigners, wants to see his/ her nation as inclusive and not exclusive and would rather have domestic minorities integrate than assimilate. Such a person avoids the traps of national ethnocentrism, and has a feeling of pride that is realistic and moderate.

We have named the second type the 'traditional cultural nationalist', who has many ties to Europe and supports his/her country's accession to the EU. This group is driven by a kind of utilitarianism. They have a high level of nationalism and ethnocentrism paired with a strong feeling of traditional cultural pride, but they support globalization if it serves the interests of the national community. Maximization of profit for the own group, which is present in both national and European space, results in an identity profile that is not free from welfare chauvinism. This is indicated by suspicion or even rejection of foreigners, a wish to close the national borders, and unwillingness to share national spoils with others. They expect moderate assimilation of domestic minorities.

We have named the third type 'national chauvinist'. It is typified by strong

17 The gist of the ethnocentric view is that one clearly overvalues his in-group, while he undervalues out-groups. Yet ethnocentrism is not nationalism. We can speak of nationalism when this ethnocentric view infuses the actions of the whole community and becomes a system-building ideology. It is a generally accepted proposition in social psychology since Sumner (Sumner, 1906) that groups have a feeling of superiority which is not only a natural source of group pride and group identity but also a source for despising and contemptousness toward the members of other groups. The ethnocentrism scale was aggregated from three items in the questionnaire, measured on five point scale: "I would rather be a citizen of [country] than of any other country in the world"; "The world would be a better place if people from other countries were more like the [country's nationality]"; "Generally speaking, [Country] is a better country than most other countries"

18 See references for national pride at footnote 9

19 See references for political and economic nationalism at footnote 8

20 See references for multiculturalism at footnote 14

21 The clustering was done using K-means method 
political nationalism, the one-sided prioritization of national interests, and strong protectionism. This group sees its nation as a closed and self-interested community that internally assimilates, closes its borders to foreigners, and in terms of national categorization it is strict and draws borders. The national chauvinist group does not show openness to the outside either and is characterized by euroscepticism. They are most likely to reject the idea of integration in the Union, and they display the lowest support for social and cultural values of integration.

In the contexts of the three types of national identity the differences by country are quite significant. Cosmopolitan patriotism is centered mostly in the Western half of Europe. Germany, the Netherlands, Sweden and France are the leaders in this respect, but other Western European countries also have a proportion of this group that is high, above thirty percent.

Traditional cultural nationalists are to be found mostly in post-socialist countries that entered the Union recently. Hungary, the Czech Republic, Slovakia, Poland and Latvia belong in this group, although this type also appears in Southern Europe (Italy and Portugal).

The most surprising finding is the relatively high proportion of national chauvinists. It is particularly interesting to note the attraction of this position in some countries of the Western region, particularly in small countries like Ireland, Austria and Finland, although it is also surprising to see the high number of people attracted to this identity in Great Britain.

To summarize, it appears that the countries of Europe are suffering a kind of value polarization, with the only difference being the pole around which the communities are polarized. In the West polarization is along the cosmopolitan vs. national socialist line, while further east polarization is in terms of traditional nationalism vs. national chauvinism. 
Figure 5: Different types of national identity patterns, percent by countries

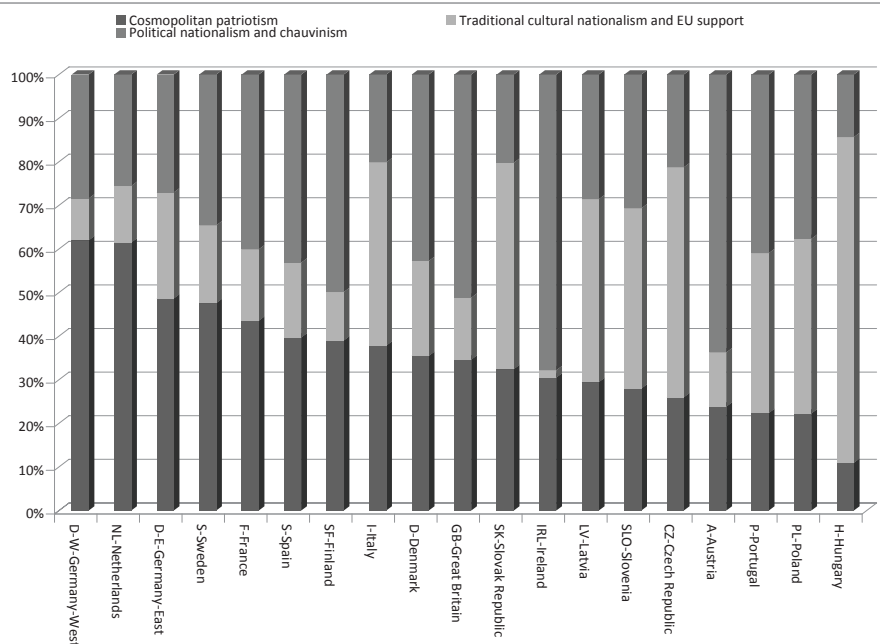

Figure 6: Different types of national identity patterns, percent

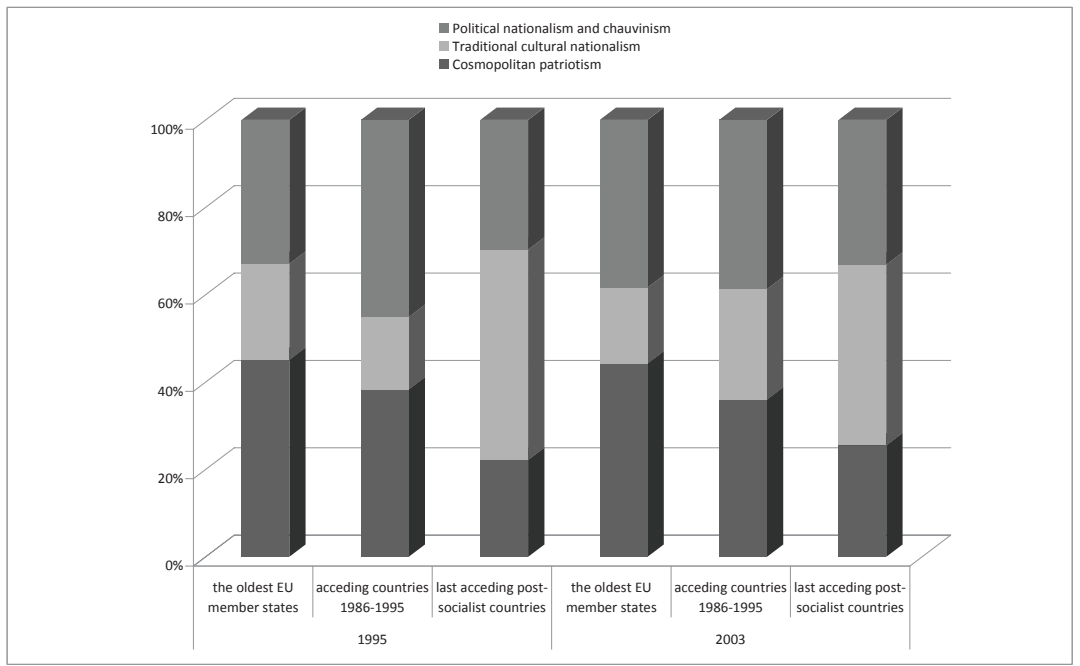

This picture is permanent in terms of time. Data collected in 1995 and in 2003 show very little change among profiles, although there may have been some rearrangement in the inner contents of the profiles. The overall view does not truly change. 


\section{CONCLUSION}

The most important lesson learned from the ISSP research series on national identity is that currently a European perspective, national identity and the process of globalization are each aspects of the everyday lives and personal identity of people living in the region. The feeling of nationality - as a factor of community identity formation and a glue of spirituality - has lost little pertinence. Although nationality aspects play a diminishing role in people's life course, career and mobility decision and in the development of personal identity, belonging to a national community is still of definitive significance in satisfying personal spiritual and symbolic needs and in the formation of collective identity. The weakening of the pertinence of borders separating the physical breadth of political states does not lead to national nihilism, but it does increase the significance of inherited cultural markers from earlier periods of national existence. This interesting dynamic develops among various identity dimensions, mainly in terms of national belonging and European identity, all in the context of strengthening globalization. The results of our analysis can be summarized from three aspects: first is the relationship between European and national identity, second is the connection between globalization and European unity, and third is the European region and immigration.

\section{The relationship between European and national identity}

The study has shown that European identity is not a melting pot. The process of unification has opened a new phase of cooperation among nations and has attained significant success in terms of efficiency, various joint development programs, and reducing inequalities among nations and regions. At the same time European must face a challenge when identifying its common cultural foundations, whereby divergent pasts, linguistic and cultural diversity and diverse social and cultural values continue to raise walls between the citizens of member states that are hard to traverse. This all strengthens Europe's value polarization, which can be a factor in the diminishing popularity of the European identity promise.

The research project uncovered dividing lines within Europe in several aspects. We can observe opposition between an identity that is traditional, closed, based on cultural pride, and often burdened by extreme nationalism on the one hand, and an identity that is modern, cosmopolitan, respectful of individual and communal rights, and based on fairness and equality on the other. An open and a closed view system exist side by side and are manifested 
in interpretations of the relations between nations, between Europe and the rest of the world, and the acceptance of immigrants. We also uncovered a nationalist vs. cosmopolitan ideological cleavage. The coexistence of these divergent mentality types on the one hand applies to Europe's historical regions, and on the other hand is present within each country, although with varying proportions and significance.

The idea of a new united Europe necessitates a new conceptualization of the nation in each member state. Our study has shown that the new conceptualization of nation can be organized around a modern idea of citizenship. The legal and political frames of citizenship are retained and enhanced with the cultural and psychological sources of national identity, thus lowering the difference between "civic nation" and "ethnic nation" paradigms (Meehan 1993; Eder 2001). At the same time we can see that the broadening of the concept of citizenship presents European citizens with an opportunity to choose between the sides of dividing lines like acceptance vs. banishment, tolerance and intolerance, political loyalty and ethnocentric insistence.

This choice is a serious challenge for member states that joined just recently. The countries of Central and Eastern Europe lag behind significantly in historic and economic terms. They lack modern political cultures and struggle with a democratic deficit, which can easily result in the dominance of traditional values and culture, allowing nationalism to fulfill the primary functions in identity formation and self-identity. This will not decrease, but will instead increase the distance between various regions.

The founding member states of the EU have had decades to adapt to the new situation brought about by economic and then political integration. In the interests of entry they limited national sovereignty, mobilized citizens to a level unprecedented in the new community of states, and dynamically developed their economies. The new wave of expansion has, however, strengthened structural and cultural polarization, which has had a significant effect on older member states. This might explain why the longer a country has experienced the Union in everyday life, the weaker its European identity, and vice versa: the more distant accession seems for a country the stronger the psychological force attracting citizens to the Union. The strong emotional ties begin to weaken significantly after accession in new member states, all while citizens are forced to acknowledge that economic and social differences between member states will not diminish in the post-accession period. 


\section{Globalization and European unification}

The unification of Europe is a part of the process of globalization, and partly a distancing of Europe from the non-European world. This duality is rife with paradoxes and tensions: when people form opinions based on individual perspectives and welfare (consumption, lifestyle, security, environmental protection) they support the former point of view, but when they pass judgments based on issues like free global economic competition, welfare and social concerns, or cultural unity, the concept of isolation and distancing is more salient. This leads to the duality whereby the idea of globalization is partly accepted, but when the world as a whole is concerned people begin to have objections to the unification project. This is all covered by the phenomenon of welfare chauvinism: globalization can be a threat to the attained high standard of living in successful countries. However, in the postsocialist region, where people's attitudes on standard of living are defined by positive expectations and not the stability of current standards, Europe and the world become the same thing, and attitudes on globalization apply to the Union just as they apply to the world.

Our data also indicated that criticism of and skepticism toward globalization increased in Europe between the observed periods. The weakening of proglobalization does not increase the chances of European success when competing with other regions of the globe, as it prognosticates a closed European consciousness. Just as nationalism as isolated in the national framework became an obstacle to development and a source of serious conflict in the twentieth century, a future strengthening of a "European nationalism" can become a competitive disadvantage for the Union. However, we must acknowledge that nationalism in the twentieth century did advance social integration in some countries, and thus European nationalism may help develop Union unity. The trick is in the balancing.

\section{The European region and the challenge of immigration}

The third controversial factor of unification is the judgment of foreigners and the phenomenon of xenophobia which - to varying degrees - is a dominant emotional type in all countries in the study, in both periods. Various countries, independent of their development and situation, express suspicion of foreigners for various reasons. In developed countries, where immigration is a definitive element of social processes, it is individual fears and frustrations that generate suspicion and rejection of foreigners. In those countries - including new 
member states - where immigration is not a mass phenomenon, the roots of xenophobia are ideological in nature and end up feeding collective nationalism, the principle of community based on cultural dominance, and the kind of traditional mentality that rejects difference outright. As the last one hundred years of globalization processes have forever broken down obstacles to free movement in the world, and as continued increases in migration appear to be unstoppable, Europe is at a crossroads. The Europe of the future will unite in the name of ethnocentrism-based opposition to strangers, or conversely, it will be able to work out and effectively communicate an identity model that ties Europe together with humanity in the name of universalism. The true test of universalism then will be how Europe handles the migration issue.

\section{LITERATURE}

Anderson, C. J., \& Reichert, M. S. (1996): Economic Benefits and Support for Membership in the EU: A Cross-National Analysis. Journal of Public Policy, 15 (3), 231-249.

Beck, Ulrich and Giddens, Anthony (2005): Nationalism has now become the enemy of Europe's nations, The Guardian, October 4., see http://www.guardian.co.uk/ politics/2005/oct/04/eu.world

Brubaker, Roger (1996): Nationalism Reframed: Nationhood and the National Question in the New Europe, Cambridge University Press.

Brubaker, Roger and Cooper, F. (2000): „Beyond identity”, Theory and Society 29, pp. 1-47.

Csepeli, György (1992): Nemzet által homályosan. Budapest, Századvég Kiadó

Csepeli, György Örkény, Antal (1999): "International Comparative Investigation into the National identity", Szociológiai Szemle, Special Issue in English, 1999., pp. 95-114.

Deflem, Mathieu; Pampel, Fred C. (1996): "The Myth of Postnational Identity: Popular Support for European Unification”, Social Forces, Vol. 75, No. 1 (Sep., 1996), pp. 119-143.

Eder,K. (2001): A Theory of Collective Identity Making Sense of the Debate on a 'European Identity', European Journal of Social Theory, Vol. 12, No. 4, 427-447 (2009)

Elder, Joseph W. (1976): “Comparative Cross-National Methodology”, Annual Review of Sociology, Vol. 2, pp. 209-230.

Erikson, E. H. (1956): "The problem of ego identity", Journal of the American Psychoanalytic Association, 4, pp. 56-121.

Franklin, M., Marsh, M., \& Wlezien, C. (1994): „Attitudes toward Europe and Referendum Votes: A Response to Siune and Svensson", Electoral Studies, 13(2), pp. 117-121.

Franklin, M., Van der Eijk, C., \& Marsh, M. (1995): „Referendum outcomes and 
trus in government: Public support for Europe in the wake of Maastricht", West European Politics, 18

Gabel, M., \& Palmer, H. (1995): „Understanding Variation in Public Support for European Integration”, European Journal of Political Research, 27(1), 3-19.

Gabel, M. (1998): „Public Support for European Integration: An Empirical Test of Five Theories", The Journal of Politics, 60(2), pp. 333-354.

Gellner, E. (1983): Nations and Nationalism. Oxford: Blackwell

Habermas, J., Cronin, C., \& De Greiff, P. (1998): The inclusion of the other: studies in political theory [Einbeziehung des Anderen.] . Cambridge, Mass.: MIT Press.

Habermas, J. and Ratzinger, J. (2005) The Dialectics of Secularization. San Francisco, CA: Ignatius Press, 2005. 85 p.

Hamilton, D.L., and Sherman, S.J. (1996): „Perceiving persons and groups”, Psychological Review, 103, pp. 336-355.

Inglehart, Roger. (1970): „Cognitive Mobilization and European Identity”, Comparative Politics, 3(1), pp. 45-70.

Inglehart, Roger (1977): The silent revolution: changing values and political styles among Western publics. Princeton, N.J: Princeton University Press

Janssen, J. I. H. (1991): Postmaterialism, Cognitive Mobilization and Public Support for European Integration. British Journal of Political Science, 21, 443-468.

Karolewski, I. P. (2006): "Citizenship and collective identity in Europe", in Karolewski I. P., \& Kaina V. (Eds.), European Identity: Theoretical Perspectives and Empirical Insights, Berlin: Lit Verlag pp. 23-59,.

Kohn, Melvin L. (1987): “Cross-National Research as an Analytic Strategy: American Sociological Association, 1987. Presidential Address", American Sociological Review, Vol. 52, No. 6 (Dec., 1987), pp. 713-731.

Meehan, E. (1993): Citizenship and the European Community. Sage, London

Richmond, Anthony H. (1996): "Ethnic Nationalism and Postindustrialism", In Hutchinson, John; Smith, Anthony D. eds. Ethnicity, Oxford University Press,. pp. 289299.

Schlesinger, Philip (1996): “Europeanness, A New Cultural Battlefield”, In Hutchinson, John; Smith, Anthony D. eds. Ethnicity, Oxford University Press, pp. 316325.

Smith, Anthony D. (1992): "National Identity and the Idea of European Unity", International Affairs, Vol. 68, No. 1 (Jan., 1992), pp. 55-76.

Sumner, W.G. (1906): Folkways, A Study of the Sociological Importance of Usage, Manners, Customs, Moves, and Moral. Dover publication, NC.

Tajfel, Henri (1982): Social Identity and Intergroup Relations, Cambridge University Press.

Wallace, Helen (1991): "The Europe that came in from the cold", International Affairs, Vol. 67, No. 4 (Oct., 1991), pp. 661-664. 